\title{
RADIOCARBON DATING BLOOD RESIDUES ON PREHISTORIC STONE TOOLS
}

\author{
D E NELSON*, T H LOY**, J S VOGEL* and J R SOUTHON*
}

ABSTRACT. We report here the first radiocarbon dating of blood residues on prehistoric stone tools. The residues found on two stone artifacts were subjected to various exploratory biochemical techniques to identify the species from which they were derived and to separate a suitable sample for dating by accelerator mass spectrometry. Although these techniques need much further development and detailed testing, the ages obtained in this first study were consistent with other data, indicating that the concept is viable. For the first time, the time of use of stone tools has been found directly, rather than by stratigraphic or other archaeologic inferential techniques.

\section{INTRODUCTION}

Trace amounts of plant and animal residues have been shown to persist on ancient stone tools for long periods of time. In particular, a butchering tool often retains residues of blood and tissue from its original use, and in most cases, the species of the animal that was butchered can be determined (Loy, 1983). Also, a number of artifacts have yielded identifiable residues of human blood (Loy, in press a, and unpub data), perhaps the results of manufacturing accidents made by the flint knappers. These findings indicate a wealth of new archaeologic information may be obtained from these residues (Loy \& Nelson, in press).

We report here the first two successful ${ }^{14} \mathrm{C}$ dates for blood residues taken from stone tools. The first was made on ca $3 \mathrm{mg}$ of carbon extracted from an unusually large blood residue taken from an artifact of known age and archaeologic association. The result obtained was in very good agreement with the expected age. The second measurement was done to test the method on a much smaller amount of residue. The artifact from which this sample was obtained was found on the surface, and there was no method of independently dating it except by a general typologic comparison with other artifacts from the region. A carbon sample of only $50 \mu \mathrm{g}$ was removed from the tool and dated, yielding an age within the expected range. These first results prove the concept, and since tool residues of $50 \mu \mathrm{g}$ or greater may be common, the method may be broadly applicable once fully developed.

\section{THE SAMPLES}

The artifact chosen for the first study was a limestone spall-flake found during excavations of the Site IgSk-7 in northern British Columbia (Loy, 1984). One surface of this tool is covered with a large quantity of an organic residue which has been identified by isoelectric focusing (as discussed later) as the blood of snowshoe hare (Lepus americanus); the residue also contains feather barbules from a Falconiforme bird. It has been suggested that the blood was used as 'glue' for fletching arrows or darts (Loy, 1984). The site from which this artifact was recovered was originally dated several years ago

\footnotetext{
* Archaeology Department, Simon Fraser University, Burnaby, British Columbia, Canada

** British Columbia Provincial Museum, Parliament Buildings, Victoria, British Columbia

'Editor's note: The late arrival of this manuscript determined its position at the end of this issue; the importance of its contents would have otherwise placed it in the first section.
} 
using the traditional $\beta$-counting method. The uppermost cultural layer yielded an age of $580 \pm 400 \mathrm{BP}$ (SFU-97) measured on wood charcoal associated with a cooking hearth. Charcoal from a second hearth near the upper limit of the middle cultural unit was dated to $1060 \pm 160 \mathrm{BP}$ (SFU98 ); the tool studied was found in the same pit $\mathrm{ca} 3 \mathrm{~cm}$ above this second hearth. The lowest cultural unit was dated to $2830 \pm 210 \mathrm{BP}$ (SFU-150) on an isolated piece of wood charcoal near the upper limit of that lowest layer. (The samples above contained carbon in the amounts $0.2 \mathrm{~g}, 0.8 \mathrm{~g}$, and $0.5 \mathrm{~g}$, respectively. These are very small for the SFU $\beta$-counting laboratory, and the uncertainties quoted reflect this.) These dates indicate that the stratigraphic sequence of the site was undisturbed, and that the age of the tool itself would be expected to be slightly younger than that of the associated hearth at $1060 \pm 160 \mathrm{BP}$.

\section{THE MEASUREMENTS}

A first simple attempt to date the blood residue failed, yielding a modern age. We had removed a $50 \mathrm{mg}$ portion and treated it in the standard manner with dilute acid and base in an attempt to remove any carbonates and the mycohyphae and rootlets that were microscopically visible in the sample. Clearly, this treatment did not remove all these contaminants, and a much more selective sample preparation method was required. We decided to extract for analysis only the high molecular weight proteinaceous material that would be expected in a blood residue.

We removed $46 \mathrm{mg}$ of the remaining residue, added $1 \mathrm{ml}$ of physiologic saline, sonicated the solution for 45 minutes to disaggregate the sample, and gently stirred it on a nutating platform for 17 hours. A $1 \mathrm{ml}$ solution of 0.9M 3-[(3-cholamidopropyl)-dimethylammonio]-1-propanesulfonate was then added, and the solution stirred for another 72 hours. ("CHAPS" is a zwitterionic detergent which has been used to disaggregate blood residues; cf Hjelmeland, 1980). The solution was centrifuged at 2000G for $10 \mathrm{~min}$ utes and the supernatant filtered through a polycarbonate filter to remove all particles larger than $8 \mu$. The resultant solution was placed in a Centricon-30 filter-concentrator (Amicon Canada, Ltd) and centrifuged at $2000 \mathrm{G}$ for 30 minutes. Ca $1 \mathrm{ml}$ of water was added, and the solution centrifuged again. This process was repeated four times to separate the large proteinaceous molecules $(>30,000 \mathrm{mw})$ from smaller contaminant molecules and from the CHAPS (mw 615). The high molecular weight material retentate in $1.5 \mathrm{ml}$ of solution was dark red-brown. All further measurements were made on this stock solution.

To identify the species of origin and, to an extent, the specific molecules isolated, we analyzed aliquots of the retentate and the filtrate by isoelectric focusing. These unknown samples, as well as control samples of animal blood (including the snowshoe hare), dried and aged human blood, commercial bovine hemoglobin, and commercial iso-electric point standard markers were applied to a $0.4 \mathrm{~mm}$ polyacrylamide gel. Following the method described by Righetti (1983), this gel was prepared at $5 \% \mathrm{~T}$, $3 \% \mathrm{C}$ in the range from $\mathrm{pH} 3.2$ to 9.1 , and run at constant power $(6 \mathrm{~W})$ to a final voltage of $1750 \mathrm{~V}$. The separated bands were then measured by densi- 
tometry, and the isoelectric point $(\mathrm{pl})$ of each peak was determined to an accuracy of ca $0.01 \mathrm{pH}$ by graphically scaling to those of the standards.

A simple "coefficient of similarity" was calculated against the blood pl values of known species. This coefficient is an index of the number of bands with identical pl values in common between separations of two samples; $i e$, it is the [number of matching values] divided by the [largest number of values]. The results for the retentate (top line, Table 1) strongly suggest that the sample is blood from a snowshoe hare; the coefficient of 0.72 is very high, and the pl values of the hemoglobin bands were an exact match with those of the control sample. The identities of the constituent molecules of the filtrate are as yet unknown, but they are clearly not strongly correlated with the control samples (line 2, Table 1).

For the ${ }^{14} \mathrm{C}$ measurements, an aliquot of the stock solution was pipetted into a quartz tube and gently evaporated to dryness. Ca $1 \mathrm{~g}$ of wire-form $\mathrm{CuO}$ and 300 Torr of ultra-pure $\mathrm{O}_{2}$ were added. The tube was then heated to ca $900^{\circ} \mathrm{C}$ to combust the material. Ca $1.8 \mathrm{mg}$ of carbon was obtained as $\mathrm{CO}_{2}$. Half this $\mathrm{CO}_{2}$ was catalytically converted to a graphite coating on $\mathrm{Fe}$ powder using the method of Vogel et al (1984) in apparatus developed specifically for sub-milligram samples. Ca $300 \mu \mathrm{g}$ of this graphite, together with the iron powder substrate, was pressed into a hole, $1.1 \mathrm{~mm}$ in diameter, in an $\mathrm{Al}$ button, and placed in the ion source of our AMS equipment. The ${ }^{14} \mathrm{C} /{ }^{13} \mathrm{C}$ ratio for the unknown was obtained with respect to that of the ${ }^{14} \mathrm{C}$ standard NBS OX-1 by repeated sequential measurements of both. Details of the measurement methods and the equipment are given by Nelson et al (1984, in press).

The ${ }^{14} \mathrm{C}$ age obtained, as calculated using an assumed $\delta^{13} \mathrm{C}$ value of $-20 \%$, was $1010 \pm 90 \mathrm{yr}$ BP (RIDDL-120). This result falls well within the general expected age range, and it correlates very well with the age of $1060 \pm 160$ BP independently obtained for the charcoal from the closely associated hearth.

The second artifact dated was a bifacially retouched knife manufac-

TABLE 1

The "similarity coefficients" comparing the isoelectric focusing data for the unknowns with those taken on known samples of human blood and on blood from a number of common northern British Columbia animals: moose (Alces alces), bison (Bison bison), caribou (Rangifer tarandus), black-tailed deer (Odocoilus columbianus) and snowshoe hare (Lepus americanus). The blood used for these comparative tests was all fresh blood that had been air-dried for at least three years as a thin smear on a microscope slide. The coefficients give an indication of the identity of the unknown, the value 1.0 indicating a perfect match. The last line in the table is an example in which the known human blood is compared with that of the other animals.

\begin{tabular}{llllllll}
\hline Sample & Human & Moose & Bison & Caribou & Deer & Hare & Identity \\
\hline IgSk7:84 & & & & & & & \\
$\quad$-retentate & 0.20 & 0.14 & 0.20 & 0.10 & 0.17 & 0.72 & Hare \\
$\quad$-filtrate & 0.12 & 0.13 & 0.10 & 0.11 & 0.09 & 0.10 & Unknown \\
IfSi $1: 6$ & 0.36 & 0.23 & 0.20 & 0.30 & 0.21 & 0.11 & Human, caribou* \\
Human & 1.0 & 0.16 & 0.32 & 0.20 & 0.28 & - & \\
\hline
\end{tabular}

* See text for other information confirming this designation 
tured from chert. This tool was found along with 23 others as part of a cache in a northern British Columbia site (IfSi-1) that has since been destroyed by river erosion and highway construction. The residue on this tool had been tested previously to determine the species of origin. Isoelectric focusing run under the same conditions as described above indicated both human and caribou (Rangifer tarandus) blood (line 3, Table 1). This possibility was subsequently confirmed by a radio-immuno-assay that yielded evidence for Cervidae albumen ( $\mathrm{G}$ Lowenstein, pers commun, 1985), and by a bead-linked, enzyme-linked immunosorbent assay that indicated the presence of human IgG ( $\mathrm{T}$ H Loy, $\mathrm{ms}$ in preparation).

We removed a small sample that we thought would be more typical of the amount of residue to be expected on tools. This was done by applying ca $50 \mu \mathrm{l}$ of physiologic saline and $50 \mu \mathrm{l}$ of $13 \mathrm{mM}$ CHAPS directly to the residue on the tool surface and then stirring, scraping, and soaking the material. The sample obtained was then processed as described above. The resultant solution was very weakly colored, and obviously contained only a little material. The entire sample was burned, yielding $50 \mu \mathrm{g}$ of carbon as $\mathrm{CO}_{2}$. This sample was very small, even by AMS standards. All the $\mathrm{CO}_{2}$ was converted to graphite and the age determinations were performed as described above. The background count rate for $50 \mu \mathrm{g}$ samples was determined from identical measurements on anthracite and found to be $\approx 2 \%$ of the rate for the modern standard. For this blood sample, all of the prepared graphite was consumed in the measurement, and ca $1 \%$ of all the ${ }^{14} \mathrm{C}$ atoms in the sample were detected.

The result was an age of $2180 \pm 160 \mathrm{yr}$ BP (RIDDL-121), calculated using an assumed $\delta^{13} \mathrm{C}$ value of $-20 \%$. As mentioned above, an independent date for this specific artifact was not possible, but the age found is in agreement with those for other artifacts of this type in northern British Columbia and the Yukon territories (Mitchell \& Loy, 1981).

\section{CONCLUSIONS}

These two determinations show that blood residues on prehistoric stone tools can be successfully ${ }^{14} \mathrm{C}$ dated. However, much remains to be done before this method can be applied routinely.

First, while there is evidence that many artifacts retain traces of bioremnants (Loy, in press b), it has yet to be firmly demonstrated whether tools retaining sufficient quantities of uncontaminated carbon are commonplace or rare. To be dated, the residues must contain at least 50 to $100 \mu \mathrm{g}$ of carbon, since this amount approaches the useful lower limit for the AMS method. To put this in perspective, a smear of recent protein such as dried blood that is $1 \mathrm{~cm}^{2}$ and $10 \mu \mathrm{m}$ thick (see Loy, 1983, Figs $1 \& 4$ ) contains ca $500 \mu \mathrm{g}$ of carbon. Thus, a ${ }^{14} \mathrm{C}$ date may be possible if even a fraction of such a smear on an artifact persists uncontaminated. Our present information suggests that tool residues of sufficient size may be common, but detailed studies must now be undertaken to determine whether this is truly the case. However, we are uncertain if this information can be obtained from existing artifact collections. Since archaeologists normally begin their examination of stone tools by scrubbing them to remove the "dirt," the amount of residue remaining on these tools may thus be quite variable. 
Next, we anticipate that a great deal of study will be required to determine the best methods for identifying and isolating the appropriate remnant bio-molecules for analysis. The techniques used here for separating the material to be dated were simple, exploratory techniques used to test the concept. They were very time consuming and not as selective as desirable. Ideally, only specifically identified molecules should be dated, and the purification techniques themselves must be carefully evaluated to ensure that contaminants are not inadvertently introduced during the preparation procedure. However, even the simple purification steps used in this study yielded excellent first results, and so we expect no unusually difficult problems in this respect.

The prospect of directly dating the time of use of a stone tool is exciting. Most archaeologic culture history is constructed from dates associated with cooking hearths or burned structures, and the artifacts are then related to the dates by stratigraphic or other inferential techniques. If, as our information suggests, bio-remnants on stone tools are found frequently and in sufficient quantity, then it will be possible for the first time to determine the temporal sequence of the development, use, and style of these artifacts by studying the objects themselves.

\section{ACKNOWLEDGMENTS}

We thank H Roman and T Brown for help with the measurements, the staff at the McMaster University Nuclear Physics Group for the use of their Tandem Accelerator, and two reviewers for helpful comments on this and future work. Support was provided by NSERC, Simon Fraser University, McMaster University, and the Friends of the BCPM.

\section{REFERENCES}

Hjelmeland, L J, 1980, A nondenaturing zwitterionic detergent for membrane biochemistry: Design and synthesis: Natl Acad Sci USA, Proc, v 77, no. 11, p 6368-6370.

Loy, T H, 1983, Prehistoric blood residues: Detection on tool surfaces and identification of species of origin: Science, v 220, p 1269-1271. tion Branch, Victoria, BC, Canada. in press a, Residue analysis

$\mathrm{H} \mathrm{J}$ and and 1984 , and 1984 seasons: Center for Archaeol Research, Univ Texas, San Antonio.

lian arch in press b, Recent advances in blood residue analysis, in Ambrose, W, ed, Austra-

Ly, T

Loy, T H and Nelson, D E, in press, Potential applications of the organic residues on ancient tools, in Blackman, J and Olin, J, eds, Internatl archaeometry conf 1984, Proc: Smithsonian Inst, Washington, DC.

Mitchell, D H and Loy, T H, 1981, An overview of Liard River Valley heritage resources: Univ Victoria, Victoria BC, Canada.

Nelson, D E, Southon, J R, Vogel, J S, Korteling, R G and Ku, T L, 1984, Progress in radioisotope dating; The SFU group, in Wolfli, W, Polach, $\mathrm{H}$ A and Andersen, $\mathrm{H} \mathrm{H}$, eds, Internat conf on accelerator mass spectrometry, 3rd, Proc: Nuclear Instruments \& Methods, v B5, p139-143.

Nelson, D E, Vogel, J S, Southon, J R and Brown, T A, 1986, Accelerator radiocarbon dating at SFU, in Stuiver, $M$ and Kra, R S, eds, Internatl ${ }^{14} \mathrm{C}$ conf, 12 th, Proc: Radiocarbon, $v 28$, no. $2 \mathrm{~A}$, in press.

Righetti, P G, 1983, Methods and theory of isoelectric focussing: Elsevier Biomed Press.

Vogel, J S, Southon, J R, Nelson, D E and Brown, T A, 1984, Performance of catalytically condensed carbon for use in accelerator mass spectrometry, in Wolfli, W, Polach, HA and Andersen, H H, eds, Internatl conf on accelerator mass spectrometry, 3rd, Proc: Nuclear
Instruments \& Methods, v B5, p 289-293. 